\title{
Effects of Junlon and Hostacerin on the Electrokinetic Properties of Spores of Aspergillus niger, Phanerochaete chrysosporium and Geotrichum candidum
}

\author{
By PENELOPE JONES, D. MOORE AND A. P. J. TRINCI* \\ Microbiology Group, Department of Cell and Structural Biology, School of Biological Sciences, \\ Williamson Building, University of Manchester, Manchester M13 9PL, UK
}

(Received 3 August 1987)

\begin{abstract}
The electrophoretic behaviour of freshly harvested spores of Aspergillus niger, Phanerochaete chrysosporium and Geotrichum candidum was determined in solution at various $\mathrm{pH}$ values. Freshly harvested spores of all three species lacked positive mobility at low $\mathrm{pH}$ values, suggesting a preponderance of acidic surface groups. Spores of the 'non-aggregating' fungus, G. candidum, had a $\mathrm{pH}$-mobility curve (peak of negative mobility between $\mathrm{pH} 3$ and 4) which was quite different to those of spores of the 'aggregating' fungi, $A$. niger and $P$. chrysosporium. The $\mathrm{pH}$-mobility curve of swollen spores of $\boldsymbol{A}$. niger which had been incubated in medium differed from that of freshly harvested spores, suggesting that changes in the wall that occur during germination alter the electrophoretic properties of the spores; swollen spores of $A$. niger, unlike freshly harvested spores, had a negative mobility maximum at $\mathrm{pH} 5 \cdot 0$.

After treatment with Junlon-110 (a polyacrylic acid), spores of all three species had similar $\mathrm{pH}$-mobility curves and all had peaks of negative mobility at $\mathrm{pH} 4 \cdot 0$. The electrophoretic mobility of spores of $P$. chrysosporium at $\mathrm{pH} 6.5$ increased linearly with the concentration $(0.01-$ $0.4 \%, \mathrm{w} / \mathrm{v}$ ) of Junlon used in the pre-treatment; electrophoretic mobility after pre-treatment with $0.005-0.1 \%(\mathrm{w} / \mathrm{v})$ Hostacerin (sodium polyacrylate) increased only up to $0.01 \%(\mathrm{w} / \mathrm{v})$ Hostacerin. The results obtained show that Junlon-110 and Hostacerin bind to fungal walls, and it is possible that spore and hyphal aggregation is reduced by these compounds because of repulsion between particles resulting from ionized carboxyl groups on the polymer.
\end{abstract}

\section{INTRODUCTION}

Moulds grow in submerged, shake-flask culture either as dispersed, filamentous mycelia (Trinci, 1972) or as mycelial aggregates which may take the form of spherical colonies known as pellets (Burkholder \& Sinnott, 1945). In the former case, all hyphae are exposed to the medium and when nutrients are present in excess, growth is exponential. However, growth of cultures containing pellets usually follows cube-root growth kinetics (Marshall \& Alexander, 1960) because nutrients (including oxygen) only diffuse into large ( $>2 \mathrm{~mm}$ diam.) pellets fast enough to maintain growth of the peripheral shell of the pellet (Pirt, 1966). In some fungi a pellet may be formed from a single spore, but in most fungi, pellets are formed from a number of spores which aggregate together, usually prior to germ-tube emergence (Galbraith \& Smith, 1969; Trinci, 1970). Hyphae (Burkholder \& Sinnott, 1945) and even small pellets (Clark, 1962) may also aggregate to form large pellets, and shake-flask cultures of some fungi, e.g. Neurospora crassa, end with the formation of a single, large mycelial aggregate. The aggregation phenomena described above explain why only a small number of pellets is formed even when cultures are inoculated with large numbers of spores (Trinci, 1970).

It is important to develop methods to control culture morphology since it can affect product formation. For example, Aspergillus niger grows faster and produces more amylase when grown as filamentous, dispersed mycelia than when grown as pellets (Elmayergi \& Scharer, 1973). 
Elmayergi et al. (1973) showed that spore aggregation in $A$. niger was reduced by the anionic polymer Carbopol-934 (carboxypolymethylene). Carbopol was adsorbed to the walls of spores and hyphae during growth and Elmayergi et al. (1973) suggested that aggregation was prevented because ionized carboxyl groups on the polymer induced electrostatic repulsion between spores and hyphae. Similarly, Trinci (1983) found that aggregation of spores and hyphae of $A$. niger was reduced when the medium contained the anionic polymers Junlon-110 or Junlon-111 (crosslinked polyacrylic acids) and he also found that these polymers were bound to the biomass.

The technique of particulate electrophoresis has provided valuable information on the properties of cell surfaces. The 'surface' studied by this technique is a region, within a few ångstroms of the actual surface, defined in terms of those ions at the surface or those ionogenic components of the peripheral zone of the cells which contribute to the electrokinetic properties of the cell (James, 1979). In the particulate micro-electrophoretic technique, the rate of migration of a cell is measured under a known applied electric field at a fixed temperature. If the hypothesis of Elmayergi et al. (1973) is correct, the electrophoretic behaviour of untreated and polymer (Junlon or Carbopol-934) treated spores should differ. The present investigation was therefore made to determine the effect of Junlon-110 and Hostacerin (sodium polyacrylate) on the pH-mobility curves of spores of A. niger, Phanerochaete chrysosporium and Geotrichum candidum; Hostacerin was included in the study because it has an effect on the morphology of cultures of $A$. niger which is similar to that of Junlon- 110 .

\section{METHODS}

Organisms and media. Phanerochaete chrysosporium Burdsall was obtained from Dr J. M. MacDonald of the University of Manchester Institute of Science and Technology, and Aspergillus niger van Tiegham and Geotrichum candidum Link ex Persoon were obtained from the culture collection of the Department of Cell and Structural

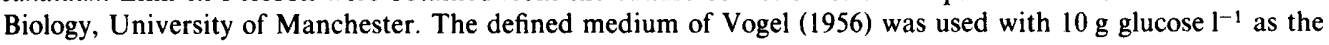
carbon source instead of sucrose. The medium was sterilized as three separate solutions: Vogel's mineral salts at $\times 50$ final concentration, glucose at $\times 5$ final concentration and (when necessary) a solution of the anionic polymer at $\times 2$ final concentration; the final volume of the medium was adjusted with sterile distilled water. The mineral salts solution was prepared and sterilized as described by Vogel (1956). The glucose and polymer solutions were sterilized by autoclaving at $115^{\circ} \mathrm{C}$ for $20 \mathrm{~min}$ and the final $\mathrm{pH}$ of the medium was adjusted to $\mathrm{pH} 6.5 \mathrm{with} 1 \mathrm{M}$ $\mathrm{NaOH}$; solutions of Junlon-110, unlike those of Hostacerin, are very acidic. When necessary, medium was solidified with agar (final concentration $15 \mathrm{~g} \mathrm{l}^{-1}$; Taiyo, Davis Gelatine). Junlon-1 10 and Hostacerin were kindly provided by Honeywill \& Stein Ltd, 69/73 Manor Road, Wallington, Surrey SM6 0BP, UK.

Spore suspensions. Spores of $A$. niger (conidiospores), $P$. chrysosporium (arthrospores) and G. candidum (arthrospores) were harvested with double-distilled water $\left(30 \mathrm{ml}\right.$ per flask) from cultures grown for $5 \mathrm{~d}$ at $25^{\circ} \mathrm{C}$ in $250 \mathrm{ml}$ conical flasks containing $50 \mathrm{ml}$ volumes of Vogel's agar medium. To minimize the variation in spore age (Fisher \& Richmond, 1970), the cultures were inoculated with a spore suspension which was spread over the surface of the agar medium. Spore suspensions were centrifuged at $1250 \mathrm{~g}\left(r_{\mathrm{av}} .7 .5 \mathrm{~cm}\right)$ for $5 \mathrm{~min}$, and, after removing the supernatant, the spores were suspended in $30 \mathrm{ml}$ sterile double-distilled water. This spore suspension was then diluted with sterile double-distilled water until it contained about $3 \times 10^{6}$ spores $\mathrm{ml}^{-1}$. Prior to measurements of electrophoretic mobility, $20 \mathrm{ml}$ spore suspension was centrifuged as before, washed and then suspended in $20 \mathrm{ml}$ of the appropriate buffer. These spores are described as 'freshly harvested'. Electrophoretic mobility is dependent on the ionic strength of the suspending medium, so care was taken to ensure that the ionic strength of each buffer was constant and identical; all buffer solutions had a final ionic strength $(I)$ of $0.05 \mathrm{~mol}^{-1}$. The buffer solutions used for measuring the electrophoretic mobility of spores were $\mathrm{HCl}$ and $\mathrm{NaCl}$ for $\mathrm{pH} 2$; $\mathrm{NaCl}$, sodium acetate, sodium barbiturate and $\mathrm{HCl}$ for $\mathrm{pH} 3$ to $9 ; \mathrm{NaCl}$, sodium acetate, sodium barbiturate and $\mathrm{NaOH}$ for $\mathrm{pH} 10$ and 11 (Gittens \& James, 1963). All buffers were made up in double-distilled water.

Some freshly harvested spores of $A$. niger were incubated in culture medium prior to measuring their electrophoretic mobility. A $20 \mathrm{ml}$ volume of spore suspension containing about $3 \times 10^{6}$ spores ml $\mathrm{m}^{-1}$ was centrifuged at $1250 \mathrm{~g}$ for $5 \mathrm{~min}$, and, after removing the supernatant, the spores were suspended in $20 \mathrm{ml}$ Vogel's medium (pH 6.5). This spore suspension was transferred to a $250 \mathrm{ml}$ conical flask and incubated at $25^{\circ} \mathrm{C}$ and 200 r.p.m. on a rotary shaker with a $2.5 \mathrm{~cm}$ stroke. The spores were harvested after $7.4 \mathrm{~h}$ when about half had formed germ tubes and about half were swollen but had not germinated. The spores were then washed and suspended in buffer as described above. The electrophoretic mobilities of the swollen spores in these preparations were measured.

Other freshly harvested spores of $A$. niger were suspended in $20 \mathrm{ml}$ volumes of Vogel's medium (pH 6.5) containing Junlon-110 or Hostacerin (final concentration about $3 \times 10^{6}$ spores per ml medium) and were then 
incubated for $1 \mathrm{~h}$ in $250 \mathrm{ml}$ conical flasks at $25^{\circ} \mathrm{C}$ and 200 r.p.m. on a rotary shaker. After incubation, each $20 \mathrm{ml}$ volume of spore suspension was diluted with $80 \mathrm{ml}$ sterile double-distilled water and centrifuged at $1250 \mathrm{~g}$ for $5 \mathrm{~min}$. The spores were then washed and suspended in buffer as described above.

Measurement of spore mohility. The cytopherometer (47 7500 ) and current regulator (39 25 47) were obtained from Zeiss. The cytopherometer had platinum electrodes and a phase-contrast optical system, and the electrophoresis cell was maintained at $25^{\circ} \mathrm{C}$. The technique is described by James (1979). Measurements of the time taken for spores to traverse $32 \mu \mathrm{m}$ were made in both directions after current reversal and each mean mobility $\left(\mu \mathrm{m} \mathrm{s}^{-1}\right)$ was obtained from at least 20 observations. The voltage was varied according to spore mobility and was taken into account when calculating the electrophoretic mobility. The conductivity of buffered spore suspension was measured at $25^{\circ} \mathrm{C}$ in a stoppered conductivity cell using a Wayne-Kerr B 221 bridge. Electrophoretic mobilities are expressed as $10^{-8} \mathrm{~m}^{2} \mathrm{~V}^{-1} \mathrm{~s}^{-1}$ (SI units) and are equivalent to $\mu \mathrm{m} \mathrm{cm} \mathrm{V}^{-1} \mathrm{~s}^{-1}$.

\section{RESULTS AND DISCUSSION}

Fig. 1 shows the electrophoretic behaviour of freshly harvested spores of $A$ : niger, $P$. chrysosporium and $G$. candidum. The $\mathrm{pH}-$ mobility curve of freshly harvested spores of $A$. niger was similar to that of $A$. niger spores that had been incubated at $\mathrm{pH} 4.5$ for $12 \mathrm{~h}$ (Seviour $\&$ Read, 1985), and freshly harvested spores of $P$. chrysosporium had a $\mathrm{pH}$-mobility curve which was similar to that of conidia of Penicillium expansum (Fisher \& Richmond, 1969). However, freshly harvested spores of G. candidum had a peak of negative spore mobility (i.e. they moved towards the anode) between $\mathrm{pH} 3$ and $\mathrm{pH} 4$ and the $\mathrm{pH}$-mobility curve of this species was unlike the $\mathrm{pH}-$ mobility curves of all other fungal spores so far studied in showing such a sharp peak (Douglas $e t$ al., 1959; Fisher, 1973; Richmond \& Fisher, 1971). However, the pH-mobility curve of G. candidum resembled that of a methicillin-sensitive strain of Staphylococcus aureus (Hill \& James, 1972).

Spores of A. niger and P. chrysosporium had isoelectric points (no mobility) at a buffer $\mathrm{pH}$ of $2 \cdot 0$, and the lack of positive mobility of the spores of all three species at low $\mathrm{pH}$ values suggests a preponderance of acidic groups on the spore surface. Seviour \& Read (1985) interpreted their results, on the basis of the known surface architecture of $A$. niger conidia, as suggesting that the predominant ionizable groups on the spore surface were possibly phosphate or carboxyl. Spores of Penicillium expansum also had an isoelectric point at pH 2.0 and Fisher \& Richmond (1969) suggested that their surface contained highly acidic phosphate groups.

Eddy \& Rudin (1958) developed a method of analysing pH-mobility curves of yeast and suggested that at least three types of ionizable groups contributed to mobility. These were: A, positive and effective below $\mathrm{pH} 4$; $\mathrm{B}$, negative and effective above $\mathrm{pH} 4$; and $\mathrm{C}$, negative, but with a constant effect on mobility through the range $\mathrm{pH} 3-9$. They suggested that the type $\mathrm{C}$ surface charge was due to phosphate groups and, tentatively, that $A$ and $B$ represented charges due to proteins in the surface layers of the wall. The phosphates were presumed to provide a negative charge over a wide $\mathrm{pH}$ range, so charged phosphates could well be responsible for the bulk of the negative charge on the spore mobilities illustrated in Fig. 1. The unusual peak in the G. candidum mobility curve around $\mathrm{pH}$ 3-4 may indicate a population of particular carboxyl groups on the spore surface which became ionized in this $\mathrm{pH}$ range.

Freshly harvested spores and swollen spores (spores incubated for $7.4 \mathrm{~h}$ prior to making mobility measurements) of $\boldsymbol{A}$. niger had different $\mathrm{pH}$-mobility curves (Figs 1 and 2 ). The peak of negative mobility of swollen spores of $A$. niger at pH 5.0 (Fig. 2) was not observed by Seviour \& Read (1985) in their studies of $A$. niger spores pre-incubated in media at pH values from 2 to 4.5 . Changes in wall composition occur during spore germination and these are presumably responsible for the difference in the $\mathrm{pH}$-mobility curves of freshly harvested and swollen conidia of $A$. niger. In the light of the previous discussion, it is possible that the spore swelling process exposes additional carboxyl groups.

Treating spores of $A$. niger, $P$. chrysosporium and $G$. candidum with $0.2 \%(\mathrm{w} / \mathrm{v})$ Junlon-1 10 in Vogel's medium changed their electrophoretic behaviour (Figs 1 and 3), indicating that the polymer is bound to the spore surface and is not removed by the washing treatment. The $\mathrm{pH}-$ mobility curve of all Junlon-110 treated spores showed peaks of negative mobility at $\mathrm{pH} 4.0$ and the mobilities of the spores of the three species at this $\mathrm{pH}$ were very similar 


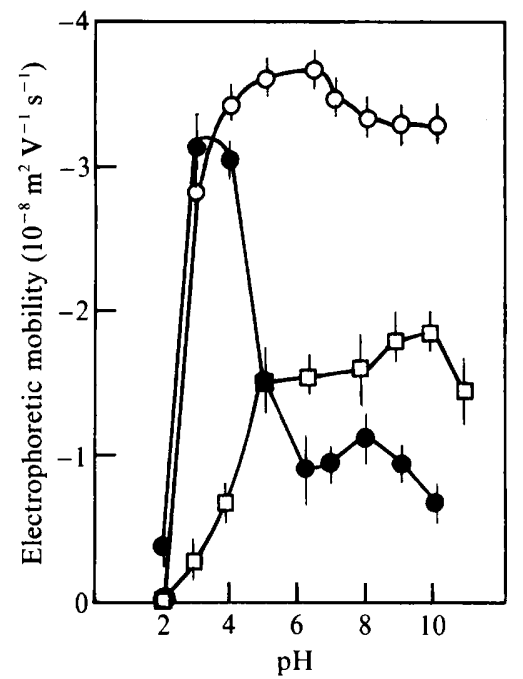

Fig. 1

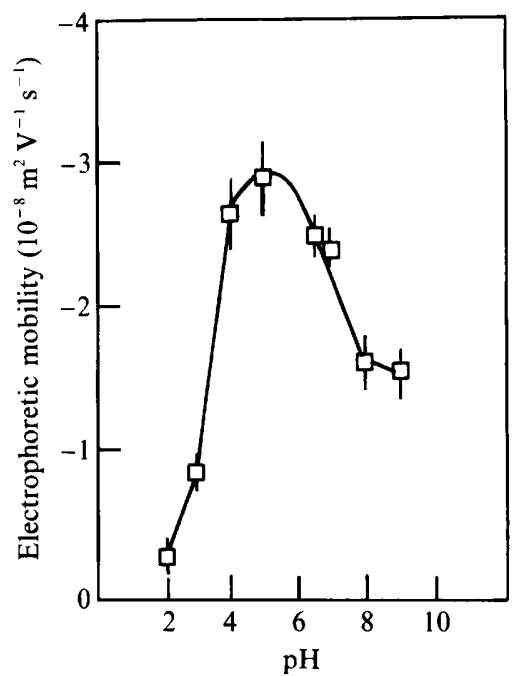

Fig. 2

Fig. 1. pH-mobility curves of freshly harvested spores of A. niger ( $\square$ ), P. chrysosporium (O) and $G$. candidum (๑). Vertical lines indicate the standard deviations from the mean.

Fig. 2. pH-mobility curve of swollen spores (incubated for $7.4 \mathrm{~h}$ at $25^{\circ} \mathrm{C}$ in Vogel's medium, pH 6.5) of $A$. niger. Vertical lines indicate standard deviations from the mean.

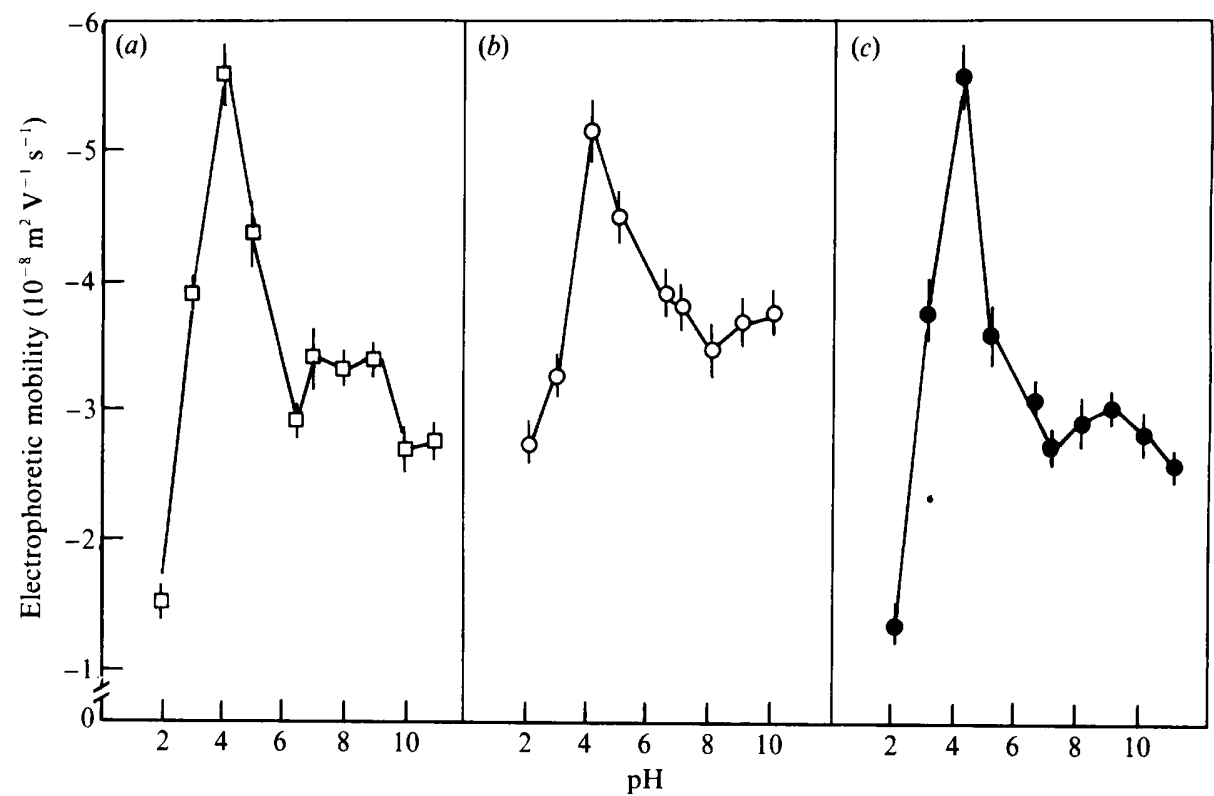

Fig. 3. pH-mobility curve of spores of $(a)$ A. niger $(\square),(b)$ P. chrysosporium $(O)$ and (c) G. candidum $(\bullet)$ after treatment with $0.2 \%(\mathrm{w} / \mathrm{v})$ Junlon- 110 in Vogel's medium at pH 6.5 for $1 \mathrm{~h}$. Vertical lines indicate standard deviations from the mean.

$\left(-5.58 \times 10^{-8} \mathrm{~m}^{2} \mathrm{~V}^{-1} \mathrm{~s}^{-1}\right.$ for A. niger, $-5 \cdot 12 \times 10^{-8} \mathrm{~m}^{2} \mathrm{~V}^{-1} \mathrm{~s}^{-1}$ for $P$. chrysosporium and $-5.65 \times 10^{-8} \mathrm{~m}^{2} \mathrm{~V}^{-1} \mathrm{~s}^{-1}$ for G. candidum).

Fig. 4 shows that the negative electrophoretic mobility of spores of $P$. chrysosporium pretreated for $1 \mathrm{~h}$ with different concentrations of Junlon-110 in Vogel's medium prior to making mobility measurements increased linearly with the concentration of Junlon-110 used in the pre- 


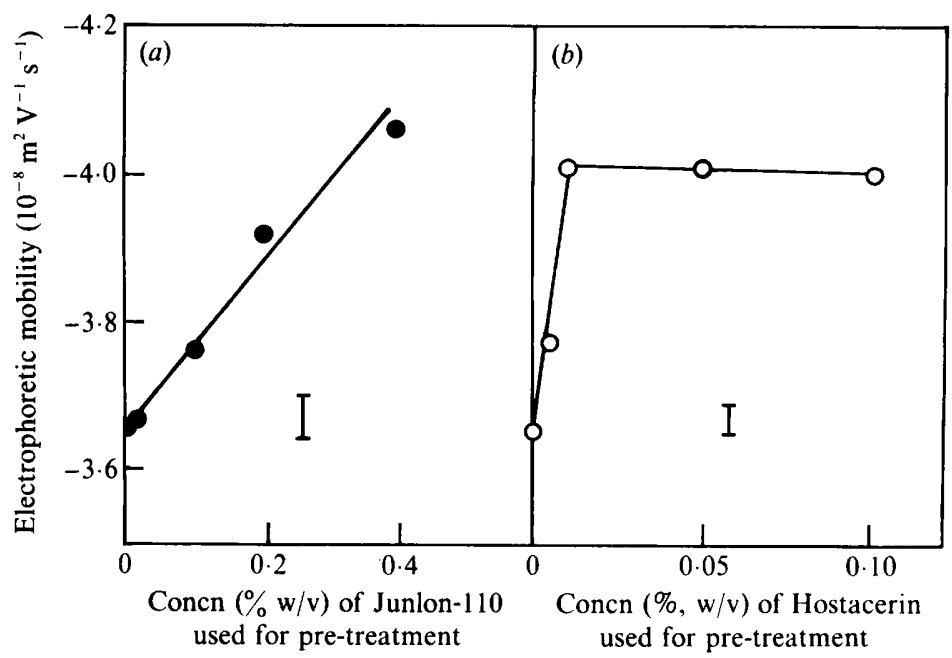

Fig. 4. Electrophoretic mobility at pH 6.5 of spores of $P$. chrysosporium before (zero reading) and after treatment with different concentrations of Junlon-110 (O) or Hostacerin $(O)$ in Vogel's medium at $\mathrm{pH} 6.5$ for $1 \mathrm{~h}$. The vertical lines give the average standard deviation from the mean.

treatment. However, the negative electrophoretic mobility of spores pre-treated with Hostacerin only increased up to a Hostacerin pre-treatment concentration of $0.01 \%(w / v)$, and thereafter remained constant. These observations suggest that Hostacerin is more effective (lower concentration required) than Junlon at increasing the negative charge on spores and that the spore surface became saturated with Hostacerin. No saturation occurred with Junlon 110; mobility increased even up to $1 \%(\mathrm{w} / \mathrm{v})$ concentration, which gave an electrophoretic mobility of $-5.52 \times 10^{-8} \mathrm{~m}^{2} \mathrm{~V}^{-1} \mathrm{~s}^{-1}$ even at $\mathrm{pH} 6.5$.

The present and previous results (Trinci, 1983) suggest that Junlon-110, like Carbopol-934 (Elmayergi et al., 1973; Seviour \& Read, 1985), is adsorbed to the surface of fungal spores and hyphae. The similarity of the $\mathrm{pH}$-mobility curves of Junlon-110-treated spores of the three species (Fig. 3) certainly suggests that their negative mobility is largely determined by surfacebound polyacrylic acid. Thus, as suggested by Elmayergi et al. (1973), Junlon-110 may prevent aggregation because of the electrostatic repulsion between the polymer-coated spores.

A key to understanding this mechanism is an adequate explanation for the cause of the aggregation in the absence of these polymers. Electrostatic attraction is an obvious possibility, and, certainly, freshly harvested (Fig. 1) and swollen (Fig. 2) spores of $A$. niger lack a net charge at $\mathrm{pH} 2.0$ and aggregation and pellet formation does not occur in cultures grown at this $\mathrm{pH}$ (Galbraith \& Smith, 1969; Seviour \& Read, 1985). Seviour \& Read (1985) discussed the paradox of accounting for aggregation by electrostatic attraction in a population of particles showing a uniformly net negative charge. One possible mechanism is for divalent cations to form 'salt bridges' between negatively charged cells (Mill, 1964). The possibility that anionic polymers reduce aggregation of fungal spores and hyphae by sequestering divalent cations from the medium and thereby preventing 'salt-bridge' formation (G. S. Byrne \& S. Ward, personal communication) can be discounted since, in our experiments, aggregation occurred in Junlonsupplemented medium when the polymer was contained within a dialysis bag (results not shown).

It is feasible for fungal spore aggregation to be due to electrical attraction because, although the spores have a net negative charge, this does not mean that they are devoid of positively charged sites. Further, a population of germinating spores will be heterogeneous in particle size, in surface electrochemistry (compare Figs 1 and 2), and in surface topography. Thus, differences in net charge between different particles, and in charge distribution over the surface of particles, can readily account for initial aggregations which then, by amplifying these differences, act as 
foci for further aggregation. However, the mechanism of aggregation is not necessarily the inverse of, nor even related in nature to, the mechanism of action of the polymers. By coating the spore with a spatially extensive and evenly distributed layer of polymer which is uniformly charged, Junlon and Hostacerin produce a population of particles in which the tendency to aggregate is abolished.

G. candidum, unlike $A$. niger and $P$. chrysosporium, does not aggregate to form pellets when grown in submerged culture (Robinson \& Smith, 1976). In seeking explanations both for aggregation and its avoidance, it may therefore be significant that freshly harvested spores of the 'non-aggregating' fungus G. candidum (Fig. 1) and Junlon-110 treated spores of $A$. niger and P. chrysosporium (Fig. 3) had similar $\mathrm{pH}$-mobility profiles.

We thank Honeywill \& Stein Ltd and BP Chemicals Ltd for grants to support this research, Dr J. D. Levi (BP International plc), Dr D. J. Fisher and Professor A. M. James for helpful comments and advice, and Long Ashton Research Station for the loan of the Zeiss cytopherometer. P.J. thanks the SERC for the award of a Research studentship.

\section{REFERENCES}

Burkholder, P. R. \& SinNott, E. W. (1945). Morphogenesis of fungus colonies in submerged shake cultures. American Journal of Botany 32, 424431.

Clark, D. S. (1962). Submerged citric acid fermentation of ferrocyanide-treated beet molasses: morphology of pellets of Aspergillus niger. Canadian Journal of Microbiology 8, 126-133.

Douglas, H. W., Collins, A. E. \& Parkinson, D. (1959). Electric charge and other surface properties of some fungal spores. Biochimica et Biophysica Acta 33, 535-538.

EDDY, A. A. \& RUdin, A. D. (1958). The structure of the yeast cell wall. 1. Identification of charged groups at the surface. Proceedings of the Royal Society B148, 419-432.

Elmayergi, H. \& Scharer, J. M. (1973). Physiological studies on Aspergillus niger fermentation with polymer addition. Journal of General and Applied Microbiology 19, 385-392.

Elmayergi, H., Scharer, J. M. \& Moo-Young, M. (1973). Effect of polymer additives on fermentation parameters in a culture of Aspergillus niger. Biotechnology and Bioengineering 15, 845-859.

Fisher, D. J. (1973). Charges on fungal spores. Pesticide Science 4, 845-860.

Fisher, D. J. \& Richmond, D. V. (1969). The electrokinetic properties of some fungal spores. Journal of General Microbiology 57, 51-60.

FisHeR, D. J. \& Richmond, D. V. (1970). The electrophoretic properties of some surface components of Penicillium conidia. Journal of General Microbiology 64, 205-214.

Galbraith, J. C. \& SMITH, J. E. (1979). Filamentous growth of Aspergillus niger in submerged shake culture. Transactions of the British Mycological Society 52, 237-246.

Gittens, G. J. \& James, A. M. (1963). Some physical investigations of the behaviour of bacterial surfaces. VI. Chemical modification of surface components. Biochimica et biophysica acta 66, 237-249.
HiLl, A. W. \& James, A. M. (1972). Surface properties of cells of methicillin-sensitive and methicillinresistant strains of Staphylococcus aureus grown at $37^{\circ} \mathrm{C}$. Microbios 6, 157-167.

JAMES, A. M. (1979). Molecular aspects of biological surfaces. Chemical Society Reviews 8, 389-418.

Marshall, K. C. \& AleXander, M. (1960). Growth characteristics of fungi and actinomycetes. Journal of Bacteriology 80, 412-416.

Mill, P. J. (1964). The nature of the interactions between flocculent cells and flocculation of Saccharomyces cerevisiae. Journal of General Microbiology 35, 61-75.

PIRT, S. J. (1966). A theory of the mode of growth of fungi in the form of pellets in submerged culture. Proceedings of the Royal Society B166, 369-373.

RICHMOND, D. V. \& Fisher, D. J. (1971). The electrophoretic mobility of micro-organisms. Advances in Microbial Physiology 9, 1-29.

Robinson, P. M. \& SMITH, J. M. (1976). Morphogenesis and growth kinetics of Geotrichum candidum in continuous culture. Transactions of the British Mycological Society 66, 413-420.

Seviour, R. J. \& READ, M. A. (1985). Electrophoretic mobility of conidia of Aspergillus niger, and the role of their surface properties in pelleting. Transactions of the British Mycological Society 84, 745-747.

TrinCI, A. P. J. (1970). Kinetics of the growth of mycelial pellets of Aspergillus nidulans. Archiv für Microbiologie 73, 353-367.

Trincl, A. P. J. (1972). Culture turbidity as a parameter of mould growth. Transactions of the British Mycological Society 58, 467-473.

Trinci, A. P. J. (1983). Effect of Junlon on morphology of Aspergillus niger and its use in making turbidity measurements of fungal growth. Transactions of the British Mycological Society 81, 408-412.

VoGEL, H. J. (1956). A convenient medium for Neurospora (medium IV). Microbial Genetics Bulletin 13, 42-44. 